International Journal of Engineering \& Technology, $7(3.2)(2018) 265-268$
International Journal of Engineering \& Technology
SPC
Website: www.sciencepubco.com/index.php/IJET
Research paper

\title{
Cassette Installation with Active Working Body in the Separating Partition
}

\author{
Mykola Nesterenko ${ }^{1}$, Ivan Nazarenko², Petro Molchanov ${ }^{3}$ \\ ${ }^{1}$ Poltava National Technical Yuri Kondratyuk University, Ukraine \\ ${ }^{2}$ Kyiv National University Of Construction And Architecture, Ukraine \\ ${ }^{3}$ Poltava National Technical Yuri Kondratyuk University, Ukraine \\ *Corresponding Author E-Mail:-Mpnesterenko@Ukr.Net
}

\begin{abstract}
The article explores the vibration form for forming single-type Ferro-concrete products, where the partition walls as an active working body has the opportunity to be involved in resonance oscillations, which allows to reduce the compaction time and reduce the energy costs for manufacturing products. Partitions dynamic characteristics the as well as the effect of the partitions oscillations on the sealing medium are studied mathematically.
\end{abstract}

Keywords: working body; resonance oscillations; cassette; concrete; vibration form.

\section{Introduction}

When forming reinforced concrete products, as a rule, is supposed to achieve the most possible economically efficient methods of using different types of energy. For these purposes, create new installations and models that meet modern production requirements. In order to mold reinforced concrete products, it is possible to use vibrating plants of different capacities with different displacement of the working element.

As a vibrating installation for molding reinforced concrete products same type, a vibrational drive is offered, in which the partitions form separate cells - cassettes, the partitions being able to be involved in resonance oscillations, which allows to reduce the compaction time and reduce the energy costs for the manufacture of products. A mathematical study of the dynamic characteristics of the oscillations of partitions makes it possible to study the effect of partitions as an active working member on a condensed medium.

In previous works [4] vibroforming units with a resonant oscillation mode of the operating body are considered. Attempts to use the operation of vibration systems in resonance mode for horizontal oscillations have been described in this paper [14]. However, the natural vibrations of the partitions themselves were not investigated. In cassette installations $[4,13]$ only vibrations excited by the vibrating drive are considered. Controlled intrinsic oscillations of partitions dividing products can be used as an additional source of excitation of vibrations in a concrete mixture during compaction of articles [15].

\section{Main body}

Consider the cassette unit consists of a metal mold, divided into individual cells by using the slip sheet - partitions. Form mounted on elastic supports, and is driven to oscillate by means of mechanical vibration exciter mounted circular oscillations.
Partitions - cells that are perpendicular to the direction of the forced oscillations are drawn into vibrations and contribute to compaction of the concrete mix. Therefore, in considering the future shape partition as active working body that interacts with the sealing medium.

Tension

$$
\begin{aligned}
& \sigma_{\mathrm{x}}=\frac{\mathrm{E}}{1-\mu^{2}}\left(\mathrm{E}_{\mathrm{x}}+\mu \mathrm{E}_{\mathrm{y}}\right)=-\frac{\mathrm{Ez}}{1-\mu^{2}}\left(\frac{\partial^{2} \omega}{\partial \mathrm{x}^{2}}+\mu \frac{\partial^{2} \omega}{\partial \mathrm{y}^{2}}\right) \\
& \sigma_{y}=\frac{E}{1-\mu^{2}}\left(\mathrm{E}_{\mathrm{x}}+\mu \mathrm{E}_{\mathrm{y}}\right)=-\frac{E z}{1-\mu^{2}}\left(\frac{\partial^{2} \omega}{\partial y^{2}}+\mu \frac{\partial^{2} \omega}{\partial x^{2}}\right) \\
& \tau_{x y}=G \gamma_{x y}=\frac{E}{2(1+\mu)} \cdot\left(-2 z \frac{\partial^{2} \omega}{\partial x \partial y}\right)=-\frac{E z}{1+\mu} \frac{\partial^{2} \omega}{\partial x \partial y}
\end{aligned}
$$

Plate oscillations variation equation

$$
\partial(\Pi-T)=0
$$

Potential energy variation

$$
\begin{aligned}
& M_{x}=\int_{-\frac{h}{2}}^{\frac{h}{2}} \sigma_{x} z d z ; \\
& M_{y}=\int_{-\frac{h}{2}}^{\frac{h}{2}} \sigma_{y} z d z ; \\
& M_{x y}=\int_{-\frac{h}{2}}^{\frac{h}{2}} \tau_{x y} z d z ;
\end{aligned}
$$

They are integrated the integrals in the last expression by parts

$$
\left(\int_{a}^{B} u d v=u v \int_{a}^{B}-\int_{a}^{B} v d u:\right.
$$




$$
\begin{aligned}
& \iint M_{x} \delta \frac{\partial^{2} \omega}{\partial x^{2}} d x d y=\tilde{\mathbb{N}} M_{x} \delta \frac{\partial \omega}{\partial x} d y-\iint \frac{\partial M_{x}}{\partial x} \delta \frac{\partial \omega}{\partial x} d x d y= \\
& =\tilde{\mathbb{N}} M_{x} \delta \frac{\partial \omega}{\partial x} d y-\tilde{\mathbb{N}} \frac{\partial M_{x}}{\partial x} \delta \omega d y+\iint \frac{\partial^{2} M_{x}}{\partial x^{2}} \delta \omega d x d y
\end{aligned}
$$

by analogy

$$
\begin{gathered}
\iint M_{y} \delta \frac{\partial^{2} \omega}{\partial y^{2}} d x d y=\tilde{\mathbb{N}} M_{y} \delta \frac{\partial \omega}{\partial y} d x-\tilde{\mathbb{N}} \frac{\partial M_{y}}{\partial y} \delta \omega d x+\iint \frac{\partial^{2} \omega}{\partial y^{2}} \delta \omega d x d y \\
\iint M_{x y} \delta \frac{\partial^{2} \omega}{\partial x \partial y}=\iint M_{x y} \frac{\partial}{\partial x} \delta \frac{\partial \omega}{\partial y} d x d y= \\
=\tilde{\mathbb{N}} M_{x y} \delta \frac{\partial \omega}{\partial y} d y-\iint \frac{\partial M_{x y}}{\partial y} \delta \frac{\partial \omega}{\partial y} d x d y=\left[M_{x y} \delta \omega\right]- \\
-\tilde{\mathbb{N}} \frac{\partial M_{x y}}{\partial y} \delta \omega d y-\tilde{N} \frac{\partial M_{x y}}{\partial x} \delta \omega d x+\iint \frac{\partial^{2} M_{x y}}{\partial x \partial y} \delta \omega d x d y
\end{gathered}
$$

The term in the square brackets is equal to zero [11]. Then the variation of the potential energy is equal to:

$\partial \Pi=-\frac{1}{2}\left\{\tilde{\mathbb{N}} M_{x} \delta \frac{\partial \omega}{\partial x} d y-\tilde{\mathbb{N}} \frac{\partial M_{x}}{\partial x} \partial \omega d y+\iint \frac{\partial^{2} M_{x}}{\partial x^{2}} \delta \omega d x d y\right.$

$+\tilde{\mathbb{N}}_{y} \delta \frac{\partial \omega}{\partial y} d x-\tilde{\mathbb{N}} \frac{\partial M_{y}}{\partial y} \delta \omega d x+\iint \frac{\partial^{2} M_{y}}{\partial y^{2}} \delta \omega d x d y$

$\left.-2 \sqrt{\sqrt{2}} \frac{\partial M_{x y}}{d y} \delta \omega d y-2 \sqrt{\mathbb{N}} \frac{\partial M_{x y}}{\partial x} \delta \omega d x+2 \iint \frac{\partial^{2} M_{x y}}{\partial x \partial y} \delta \omega d x d y\right\}$

$-\frac{1}{2} \iint_{A} q \delta \omega d x d y=-\frac{1}{2}\left\{\tilde{\mathbb{N}}_{x} \delta \frac{\partial \omega}{\partial x} d y+\tilde{\mathbb{N}} M_{y} \delta \frac{\partial \omega}{\partial y} d x\right.$

$\left.\left.-\left[\tilde{\mathbb{N}} \frac{\partial M_{x}}{\partial x}+2 \frac{\partial M_{x y}}{\partial y}\right] d y-\tilde{\mathbb{N}} \frac{\partial M_{y}}{\partial y}+2 \frac{\partial M_{x y}}{\partial x}\right] d x\right\} \delta \omega$

$\left.+\iint\left(\frac{\partial M_{x}}{\partial x^{2}}+2 \frac{\partial^{2} M_{x y}}{\partial x \partial y}+\frac{\partial^{2} M_{y}}{\partial y^{2}}\right) d x d y \delta \omega\right\}$

$-\frac{1}{2} \iint_{A} q \delta \omega d x d y=\frac{1}{2} \iint\left(\frac{\partial^{2} M_{x}}{\partial x^{2}}+2 \frac{\partial^{2} M_{x y}}{\partial x \partial y}\right.$

$\left.+\frac{\partial^{2} M_{y}}{\partial y^{2}}+q\right) \delta \omega d x d y$

In the formulas (5) and (7) the notation summary of shear forces $\left(Q_{x}, Q_{y}\right)$, bending $\left(M_{x}, M_{y}\right)$ and torsional moments $\left(M_{x y}\right)$.

$$
\begin{gathered}
Q_{x}=-\left(\frac{\partial M_{x}}{\partial x}+2 \frac{\partial M_{x y}}{\partial y}\right)=-D\left[\frac{\partial^{3} \omega}{\partial x^{3}}+\mu \frac{\partial^{3} \omega}{\partial x \partial y^{2}}\right. \\
\left.+2(1-\mu) \frac{\partial^{3} \omega}{\partial x \partial y^{2}}\right]=-D\left[\frac{\partial^{3} \omega}{\partial x^{3}}+(2-\mu) \frac{\partial^{3} \omega}{\partial x \partial x^{2}}\right] \\
Q_{y}=-D\left[\frac{\partial^{3} \omega}{\partial y^{3}}+(2-\mu) \frac{\partial^{3} \omega}{\partial x^{2} \partial y}\right]=D\left[\frac{\partial M_{y}}{\partial y}+(2-\mu) \frac{\partial M_{x y}}{\partial x}\right] \\
M_{x}=-\int_{-\frac{h}{2}}^{\frac{h}{2}} \frac{E z^{2}}{1-\mu^{2}}\left(\frac{\partial^{2} \omega}{\partial x^{2}}+\mu \frac{\partial^{2} \omega}{\partial y^{2}}\right) d z=-D\left(\frac{\partial^{2} \omega}{\partial x^{2}}+\mu \frac{\partial^{2} \omega}{\partial y^{2}}\right) ; \\
M_{y}=-D\left(\frac{\partial^{2} \omega}{\partial y^{2}}+\mu \frac{\partial^{2} \omega}{\partial x^{2}}\right) ; M_{x y}=-D(1-\mu) \frac{\partial^{2} \omega}{\partial x \partial y} \\
\text { D }=\frac{E^{3}}{12\left(1-\mu^{2}\right)}-\text { coefficient of the cylindrical rigidity h - } \\
\text { thickness of the plate. }
\end{gathered}
$$

Integrals of equation (7) form the boundary conditions on the contour of the plate.
Four types of boundary conditions for the investigated rectangular plate of constant thickness are discussed:

- During the bending moment and shear force at the free edge are equal to zero:

$$
\begin{aligned}
& \left.\mathrm{M}_{\mathrm{x}}(\mathrm{x}, \mathrm{y})\right|_{\substack{x=0 \\
x=a}}=0, \quad \mathrm{M}_{\mathrm{x}}=-\mathrm{D}\left(\frac{\partial^{2} \omega}{\partial \mathrm{x}^{2}}+\mu \frac{\partial^{2} \omega}{\partial \mathrm{y}^{2}}\right)=0, \\
& \left.\mathrm{Q}_{x}(\mathrm{x}, \mathrm{y})\right|_{\substack{x=0 \\
x=b}}=0, \quad \mathrm{Q}_{\mathrm{x}}=-\mathrm{D}\left[\frac{\partial^{3} \omega}{\partial \mathrm{x}^{3}}+(2-\mu) \frac{\partial^{3} \omega}{\partial \mathrm{x} \partial \mathrm{y}^{2}}\right]=0 \text {. } \\
& \left.\mathrm{M}_{y}(\mathrm{x}, \mathrm{y})\right|_{\substack{y=0 \\
y=b}}=0, \quad \mathrm{M}_{\mathrm{y}}=-\mathrm{D}\left(\frac{\partial^{2} \omega}{\partial \mathrm{y}^{2}}+\mu \frac{\partial^{2} \omega}{\partial \mathrm{x}^{2}}\right)=0, \\
& \left.\mathrm{Q}_{y}(\mathrm{x}, \mathrm{y})\right|_{\substack{y=0 \\
y=b}}=0, \quad \mathrm{Q}_{\mathrm{y}}=-\mathrm{D}\left[\frac{\partial^{3} \omega}{\partial \mathrm{y}^{3}}+(2-\mu) \frac{\partial^{3} \omega}{\partial \mathrm{y}^{2} \mathrm{x}^{2}}\right]=0 .
\end{aligned}
$$

- And at a deflection angle of rotation fixed edge section, for example at

$\mathrm{x}=\mathrm{a}$, is equal to zero:

$$
\left\{\begin{array} { c } 
{ \omega = 0 } \\
{ \frac { \partial \omega } { \partial x } = 0 }
\end{array} \left\{\begin{array}{c}
\omega=0 \\
\frac{\partial \omega}{\partial y}=0
\end{array}\right.\right.
$$

- At the trough and the general point pivotally supported edges are equal to zero:

$$
\begin{gathered}
\omega=0 ; M_{x}=-D\left(\frac{\partial^{2} \omega}{\partial x^{2}}+\mu \frac{\partial^{2} \omega}{\partial y^{2}}\right)=0 ; \\
\left\{\begin{array}{c}
\omega=0 \\
M_{y}=-D\left(\frac{\partial^{2} \omega}{\partial y^{2}}+\mu \frac{\partial^{2} \omega}{\partial x^{2}}\right)=0 .
\end{array}\right.
\end{gathered}
$$

The variation of the kinetic energy is equal to:

$\delta T=\frac{1}{2} \int_{A} \rho h \delta\left(\frac{\partial \omega}{\partial \mathrm{t}}\right)^{2} \mathrm{dxdy}$.

After substitution of (12) and (7) in the variational equation of oscillations plate (2) and the separation of parts in charge of boundary conditions, variations of an equation of transverse vibrations of a thin elastic plate :

$$
\begin{aligned}
& \frac{\partial^{2} \mathrm{M}_{x}}{\partial \mathrm{x}^{2}}+2 \frac{\partial^{2} \mathrm{M}_{\mathrm{xy}}}{\partial x \partial \mathrm{y}}+\frac{\partial^{2} M_{y}}{\partial \mathrm{y}^{2}}+q+\rho \mathrm{h} \frac{\partial^{2} \omega}{\partial \mathrm{t}^{2}}= \\
& =\mathrm{D}\left[\frac{\partial^{4} \omega}{\partial \mathrm{x}^{4}}+2 \frac{\partial^{4} \omega}{\partial \mathrm{x}^{2} \partial \mathrm{y}^{2}}+\frac{\partial^{2} \omega}{\partial \mathrm{y}^{2}}\right]+\mathrm{q}+\rho \mathrm{h} \frac{\partial^{2} \omega}{\partial \mathrm{t}^{2}}=0,
\end{aligned}
$$

For free oscillations at $\mathrm{q}=0$ the solution is found in the form of : $\omega(x, y, t)=\omega(x, y) \sin (p t+\alpha)$

Accordingly, equation (13) will form

$$
\mathrm{D}\left[\frac{\partial^{4} \omega}{\partial \mathrm{x}^{4}}+2 \frac{\partial^{4} \omega}{\partial \mathrm{x}^{2} \partial \mathrm{y}^{2}}+\frac{\partial^{2} \omega}{\partial \mathrm{y}^{2}}\right]+\rho \mathrm{h} \frac{\partial^{2} \omega}{\partial \mathrm{t}^{2}}=0
$$

Consider the boundary conditions for various cases, securing the ends of beams (Table 1) 
Table 1: Boundary conditions for various cases, securing active working body ends

\begin{tabular}{|c|c|c|c|c|c|c|}
\hline \multicolumn{2}{|c|}{ Fixing ends } & \multirow{2}{*}{$\begin{array}{l}x \\
0\end{array}$} & \multirow{2}{*}{$\begin{array}{c}M \\
0\end{array}$} & \multirow{2}{*}{$\frac{\frac{d \omega}{d x}}{*}$} & \multirow{2}{*}{$\frac{d M}{d x}$} & \multirow{2}{*}{$\begin{array}{c}\omega \\
0\end{array}$} \\
\hline 0 & $l$ & & & & & \\
\hline तोग & $\frac{8}{1111}$ & $l$ & 0 & $*$ & $*$ & 0 \\
\hline 0 & $l$ & 0 & $*$ & 0 & $*$ & 0 \\
\hline$\lambda$ & $\frac{8}{171 / 1}$ & $l$ & 0 & $* w$ & $*$ & 0 \\
\hline 0 & $l$ & 0 & $*$ & 0 & $*$ & 0 \\
\hline & & $l$ & $*$ & 0 & $*$ & 0 \\
\hline 0 & $l$ & 0 & $*$ & 0 & $*$ & 0 \\
\hline AX & & $l$ & 0 & $*$ & 0 & $*$ \\
\hline
\end{tabular}

$\mathrm{X}_{\mathrm{m}}(\mathrm{x}), \mathrm{Y}_{\mathrm{n}}(\mathrm{y})$ - beam functions.

Frequency of oscillation is determined by the formula

$\omega=\frac{\mathrm{k}_{\mathrm{n}}^{2}}{\mathrm{a}^{2}} \sqrt{\frac{\mathrm{D}}{\rho \mathrm{h}}}$

where

$\mathrm{k}_{\mathrm{n}, \mathrm{m}}^{2}=\pi^{2} \lambda ; \lambda_{\mathrm{n}, \mathrm{m}}^{2}=\left(\mathrm{G}_{\mathrm{x}}^{4}\right)_{\mathrm{n}}+\frac{\mathrm{a}^{4}}{\mathrm{~b}^{4}}\left(\mathrm{G}_{\mathrm{y}}^{4}\right)_{\mathrm{m}}+$

$+2 \frac{\mathrm{a}^{2}}{\mathrm{~b}^{2}}\left[v\left(\mathrm{H}_{\mathrm{x}}\right)_{\mathrm{n}}\left(\mathrm{H}_{\mathrm{y}}\right)_{\mathrm{m}}+(1-v)\left(\mathrm{J}_{\mathrm{x}}\right)_{\mathrm{n}}\left(\mathrm{J}_{\mathrm{y}}\right)_{\mathrm{m}}\right]$.

Two cases of boundary conditions are considered:

- Two opposite sides are rigidly fixed, and two others - free;

- Two opposite sides hinged, the other two are free.

The first case corresponds to the rigid mounting (welded) plate to form the walls, and the second case - reliance free (detachable hinged) plates.

For the first case the beam function is written as

$$
\begin{aligned}
& \mathrm{X}_{\mathrm{m}}=\operatorname{ch} \frac{\mathrm{k}_{\mathrm{m}} \mathrm{x}}{1}-\cos \frac{\mathrm{k}_{\mathrm{m}} \mathrm{x}}{1}-\sigma_{\mathrm{m}}\left(\operatorname{sh} \frac{\mathrm{k}_{\mathrm{m}} \mathrm{x}}{1}-\sin \frac{\mathrm{k}_{\mathrm{m}} \mathrm{x}}{1}\right) \\
& \mathrm{Y}_{\mathrm{n}}=\operatorname{ch} \frac{\mathrm{k}_{\mathrm{n}} \mathrm{x}}{1}-\cos \frac{\mathrm{k}_{\mathrm{n}} \mathrm{x}}{1}-\sigma_{\mathrm{n}}\left(\operatorname{sh} \frac{\mathrm{k}_{\mathrm{n}} \mathrm{y}}{1}-\sin \frac{\mathrm{k}_{\mathrm{n}} \mathrm{y}}{1}\right)
\end{aligned}
$$

for the second case:

$$
\begin{aligned}
& \mathrm{X}_{\mathrm{m}}=\operatorname{ch} \frac{\mathrm{k}_{\mathrm{m}} \mathrm{x}}{1}-\cos \frac{\mathrm{k}_{\mathrm{m}} \mathrm{x}}{1}-\sigma_{\mathrm{m}}\left(\operatorname{sh} \frac{\mathrm{k}_{\mathrm{m}} \mathrm{x}}{1}-\sin \frac{\mathrm{k}_{\mathrm{m}} \mathrm{x}}{1}\right) \\
& \mathrm{Y}_{\mathrm{n}}=\operatorname{ch} \frac{\mathrm{k}_{\mathrm{n}} \mathrm{x}}{1}-\cos \frac{\mathrm{k}_{\mathrm{n}} \mathrm{x}}{1}-\sigma_{\mathrm{n}}\left(\operatorname{sh} \frac{\mathrm{k}_{\mathrm{n}} \mathrm{y}}{1}-\sin \frac{\mathrm{k}_{\mathrm{n}} \mathrm{y}}{1}\right)
\end{aligned}
$$

For the studied plates function $\mathrm{G}_{\mathrm{x}}, \mathrm{G}_{\mathrm{y}}, \mathrm{H}_{\mathrm{x}}, \mathrm{H}_{\mathrm{y}}, \mathrm{J}_{\mathrm{x}}, \mathrm{J}_{\mathrm{y}}$ will be equal to:

- The first case

$$
\left(\mathrm{G}_{x}\right)_{m}= \begin{cases}1.506, & m=2 \\ m-\frac{1}{2}, & m=3,4,5 \ldots\end{cases}
$$

$$
\begin{gathered}
\left(\mathrm{H}_{x}\right)_{m}=\left\{\begin{array}{c}
1.248, \\
\left(m-\frac{1}{2}\right)^{2}\left[1-\frac{2}{\left(m-\frac{1}{2}\right) \pi}\right] .
\end{array}\right. \\
\left(\mathrm{J}_{x}\right)_{m}=\left\{\begin{array}{c}
1.248, \\
\left(m-\frac{1}{2}\right)^{2}\left[1-\frac{2}{\left(m-\frac{1}{2}\right) \pi}\right] .
\end{array}\right.
\end{gathered}
$$

$\left(\mathrm{G}_{y}\right)_{n}= \begin{cases}1.506, & m=2 \\ n-\frac{1}{2} . & m=3,4,5 \ldots\end{cases}$

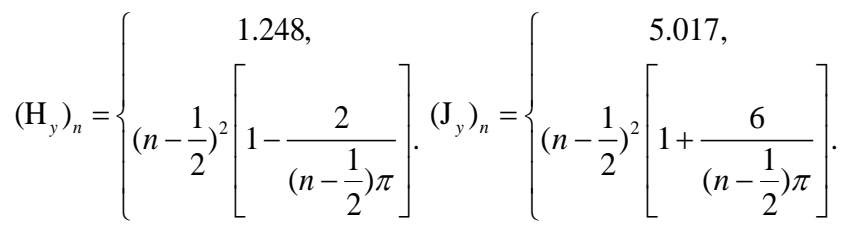

- The second case

$$
\left(\mathrm{G}_{x}\right)_{m}= \begin{cases}1.506, & m=2 \\ m-\frac{1}{2}, & m=3,4,5 \ldots\end{cases}
$$$$
\left(\mathrm{H}_{x}\right)_{m}=\left\{\begin{array}{c}
1.248, \\
\left(m-\frac{1}{2}\right)^{2}\left[1-\frac{2}{\left(m-\frac{1}{2}\right) \pi}\right] .
\end{array}\right.
$$$$
\left(\mathrm{J}_{x}\right)_{m}=\left\{\begin{array}{c}
5.017 \\
\left(m-\frac{1}{2}\right)^{2}\left[1+\frac{6}{\left(m-\frac{1}{2}\right) \pi}\right] .
\end{array}\right.
$$

$$
\begin{aligned}
& \left(\mathrm{G}_{y}\right)_{n}=n-1 \quad m=3,4,5 \ldots \quad\left(\mathrm{H}_{y}\right)_{n}=(n-1)^{2} \\
& \left(\mathrm{~J}_{y}\right)_{n}=(n-1)^{2}
\end{aligned}
$$

\section{Conclusion}

1. Based on the options analysis for the installation of an active working body for the formation of concrete products, presented in the plate form, oscillations resonance frequencies calculation is performed, with different viscoelastic fixings.

2. The obtained results allow solving the problem of resonance frequencies of the oscillations of the working element taking into account the medium influence in order to determine the maximum energy transferred from its concrete mixture, which will allow reducing the energy costs for the formation of concrete products.

3. Plate vibrations are considered for different attachment cases when the two opposite sides are rigidly fixed, and the other two are free and the two opposite sides are hinged, the other two are free. 


\section{References}

[1] Babakov I.M. (2004), Theory of the oscillations / I.M. Babakov, M. Drofa, - p. 343-364.

[2] Vasilenko M.V. (2004), Theory of the oscillations and resistence of motion / M.V. Vasilenko, O.M. Alekseichuk K.: Vyscha skola, P. 391-411.

[3] Korobko B. (2016), Investigation of energy consumption in the course of plastering machine's work, Eastern-European Journal of Enterprise Technologies, 4/8 (82), 4 - 11. DOI:10.15587/17294061.2016 .73336

[4] Solovjov V.V. (2015), Investigation of strain-stress state round the borehole massif containing the plastic rocks /V.V. Solovjov, N.N.Roy // Metallurgical and mining industry. -№8.- p. 555-558.

[5] Nesterenko , M.P. (2005), Vibration site with spatial oscillations for the making reinforceconcrete wares of wide nomenclature / M.P. Nesterenko / / Zbirnik naukovyi Prace ( machine-building , budivnitstvo ). - Poltava: PoltNTU . - Vol . 16. - P. 177-181

[6] Nesterenko, M.P. (1996), Universal vibrostend spatial oscillations / M.P.Nesterenko, O.V. Orisenko , V.V. Shulgin // Progressive tehnology and mashines for production, bealding materials, components and structures: Proc . Reports. The first ukrainian scientific and practical conference. - Poltava,- P. 59.

[7] Olehnovich K.A. (1991), Consumer quality modern vibraton platformes / K.A. Olehnovich, Y.I. Vinogradov, N.P. Nesterenko / Building and road machines, - № 8. - P.14-16 .

[8] Rektoris K. (1985), Variational methods in mathematical physics and engineering / K. Rektoris, M., Mir, - S. 272.

[9] Sivko, V.Y. (2000), Some questions of theory of building materials and composites / V.J. Sivko , M.P. Nesterenko / / Collection of science works ( machine-building, budivnitstvo ) . - Poltava: PoltNTU, - Vol. 6. - P. 84-89.

[10] Sivko V.Y. (1994), Mechanical machinery companies of building wares: - K.: ISDO, - 359 p.

[11] Chubuk, U.F. (1985), Vibrating machines for compacting concrete mixtures / U.F. Chubuk, I.I. Nazarenko, V.N. Garnets . - K.: Higher School, - $168 \mathrm{p}$.

[12] Nesterenko M.P., Molchanov P.O. (2014), Study of vibrations of plate of oscillation cassette setting as active working organ / M.P. Nesterenko, P.O. Molchanov // Conference reports materials «Problems of energ and nature use 2013» (Poltava National Technical Yuri Kondratyuk University, University of Tuzla, China Universitety of Petroleum). -Budapest, - P. 146-151.

[13] Carpinteri A., Corrado M., Paggi M. (2011), An analytical model based on strain localisation for the study of size-scale and slenderness effects in uniaxial compression tests, Strain 47, 351362 .

[14] Chen X. , Wu S., Zhou J. (2013), Experimental study and analytical formulation of mechanical behavior of concrete, Construction and Buildings Materials 47, 662-670.

[15] Lyakh M.M., Savyk V.M., Molchanov P.O. (2016) Improving the efficiency of foamgenerating devices of pump-circulative systems of drilling sets // Rozrobka rodovish korisnih kopalin. Dnipropetrovsk: Naukovij visnik NGU,- № 3-S.23-30. 